\title{
Síndrome hemolítico urémico atípico, revisión de la literatura y documento de consenso. Enfoque diagnóstico y tratamiento
}

\author{
Juan Pablo Córdoba ${ }^{1}$, Kateir Mariel Contreras ${ }^{1}$ Carolina Larrarte ${ }^{2}$, Zilac Espitaleta ${ }^{1}$, Luz \\ Estela González ${ }^{3}$, Milton Ibarra ${ }^{4}$, Jorge Enrique Echeverri ${ }^{5}$, Martha Carrascal ${ }^{6}$, \\ Luis Alfonso Valderrama ${ }^{7}$, Mayerly Prada ${ }^{8}$ \\ ${ }^{1}$ Unidad Renal, Hospital Universitario San Ignacio. Pontificia Universidad Javeriana, Bogotá, Colombia \\ 2 \\ Unidad Renal RTS-Santa Clara, Hospital Santa Clara, Bogotá, Colombia

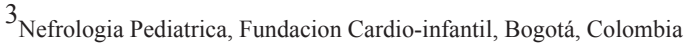 \\ ${ }^{4}$ Nefrologia Pediatrica, Hospital Universitario Moncaleano, Neiva, Colombia \\ ${ }^{5}$ Servicio de nefrología, Hospital Militar Central, Bogotá, Colombia. \\ $6_{\text {Nefrologia Pediatrica, Fundacion Clinica Infantil Club Noel. Cali, Colombia }}$ \\ ${ }^{7}$ Nefrologia, Centro Medico Imbanaco. Cali, Colombia \\ ${ }^{8}$ Nefrologia Pediatrica, Fundacion Cardio-infantil, Bogotá, Colombia
}

Todos los autores son miembros del Grupo Colombiano de Interés en SHUa y enfermedades del complemento.

\begin{abstract}
Resumen
El Síndrome Hemolítico Urémico atípico (SHUa) es una enfermedad ultra-huérfana; más del 50\% de los pacientes muere, necesita terapia de remplazo renal o sufre insuficiencia renal terminal dentro del primer año de diagnóstico. Con el tratamiento de soporte actual (plasmaféresis o infusión deplasma) 9-15\% de los pacientes de SHUa mueren dentro del lapso de 1 año, después de una manifestación clínica de hemólisis. Las consecuencias severas de esta enfermedad refuerzan la importancia del diagnóstico y tratamiento temprano. Las manifestaciones clínicas incluyen la triada clásica de anemia microangiopática, trombocitopenia y daño a otros órganos, donde la insuficiencia renal es la manifestación más común, frecuentemente asociada a otras complicaciones tales como neurológicas, cardíacas y gastrointestinales.

Las mutaciones en las proteínas reguladoras del sistema del complemento son reconocidas como las causas de este síndrome; sin embargo, no se identifican en todos los pacientes con diagnóstico de SHUa. Existe una alta tasa de pérdida del injerto postrasplante renal, en aproximadamente $60 \%$ de los casos.La plasmaféresis, considerada como terapia de primera línea, no ha demostrado resultados satisfactorios a largo plazo. Desde el año 2011 está disponible en Colombia un anticuerpo monoclonal recombinante dirigido contra el complemento a nivel C5 (eculizumab), medicamento único aprobado para el tratamiento del SHUa. Este tratamiento ha demostrado mejorar, de manera significativa, el pronóstico y la progresión de la enfermedad, y es considerado la primera línea de terapia hoy en día.
\end{abstract}

Palabras clave: Síndrome hemolitico uremico atipico. Complemento. Microangiopatía trombótica. Plasmaferesis. Eculizumab. Transplante renal. 
Atypical Hemolytic Uremic Syndrome, literature revision and consensus document. Diagnosis and treatment

\begin{abstract}
Summary
Atypical Hemolytic Uremic Syndrome is an ultra-orphan disease, more than $50 \%$ of patients die, need renal replacement therapy or have permanent renal failure within the first year of diagnostic. With current supportive care $9-15 \%$ of aHUS patients die within 1 year following a clinical manifestation of aHUS. Severe consequences of this disease reinforce the early diagnostic and treatment importance. Clinical manifestations of this disease include the classic triad of microangiopatic anemia, thrombocytopenia and end organ damage where the renal failure is the most common manifestation, although not the only one as neurological, cardiac and gastrointestinal complications are also apparent.

Mutations on the complement system regulating proteins are recognized as the cause of this syndrome; however they are not identified in all patients as new mutations are continuously being identified. It has a high rate post-transplantation graft loss in $60 \%$ of the cases. Most known therapy for this disease, considered as the first line therapy was plasmapheresis; however it shows very poor results. Since 2011 we have a recombinant monoclonal antibody targeted to the complement component C5 (eculizumab), the only approved for the treatment of aHUS, which has proven to significantly improve the disease prognosis and progression, and is considered the first line therapy.
\end{abstract}

Key words: Atypical Hemolytic Uremic Syndrome, Complement. Thrombotic microangiopathy. Plasmapheresis. Eculizumab. Renal transplant

\section{Introducción}

L as microangiopatías trombóticas (MAT), descritas por Symmers en 1952, han sido clasificadas comúnmente como púrpura trombocitopénica trombótica (PTT) y síndrome hemolítico urémico (SHU); definidas clínicamente por los órganos involucrados durante la presentación; en el SHU prevalece el trastorno renal mientras que en la PTT prevalece el compromiso del sistema nervioso central. A su vez, el SHU se ha dividido históricamente en 2 tipos; el típico, asociado a diarrea y el atípico (SHUa), no asociado a diarrea.

Con los avances en investigación y posibilidad de tratamiento diferente según cada entidad, no solo es posible hacer un diagnóstico más preciso sino que es necesario diferenciar entre PTT/SHU/SHUa. El descubrimiento de la deficiencia severa de ADAMTS-13 como causa de la PTT y de algunas mutaciones en el sistema del complemento en el caso del SHUa, además de la identificación de la E. coli entero invasiva como causa del SHU STEC, sugieren que el tratamiento de estas entidades debe ser diferente y dirigido a su causa. Se debe tener en cuenta que los pacientes con SHUa también pueden presentar dia- rrea, como una manifestación independiente, por lo tanto ya no se usan los términos de SHU con diarrea positiva o diarrea negativa ni son adecuados y deberían ser remplazados por SHUa vs. SHU STEC.

El SHUa es una enfermedad ultra-rara, con una prevalencia de 3.3 pacientes por millón de habitantes, con comportamiento devastador, progresivo y potencialmente fatal debido a la activación sistémica no controlada del complemento ${ }^{1-6}$. Nueve a quince por ciento de los pacientes mueren después del primer año de presentar la manifestación de MAT y hasta $33 \%$ de los pacientes con SHUa progresan a enfermedad renal crónica (ERC) estadio 5 (en la era pre-eculizumab) $)^{2,7}$. Si bien el riñón es el órgano más frecuentemente comprometido, hasta el 63\% de los pacientes de SHUa presentan otras complicaciones y daños orgánicos potencialmente fatales, que incluyen complicaciones neurológicas, gastrointestinales y cardiovasculares ${ }^{1,6,8-12}$. Aquellos pacientes con SHUa que sobreviven a la manifestación clínica inicial, experimentan con frecuencia un deterioro significativo de la calidad de vida y riesgo de morbilidad adicional y mortalidad prematura ${ }^{1,2,6,13}$.

Con el objetivo de elaborar un documento actualizado para el diagnóstico, identificación y tratamiento 
de pacientes con SHUa en nuestro país, se realizaron 2 reuniones presenciales por el grupo de investigadores interesados, se dividieron los temas a abordar en 4 grupos diferentes (fisiopatología y diagnóstico, mutaciones genéticas, tratamiento y trasplante renal). Se socializó el material recolectado y los documentos analizados con todo el grupo, y se realizaron recomendaciones para cada área de interés. El presente documento recoge las principales conclusiones y recomendaciones de dichas reuniones y grupos de trabajo.

\section{Estrategia de búsqueda}

La búsqueda de la literatura disponible, para la realización de este trabajo, se realizó con el siguiente término MESH "Atypical hemolytic uremic síndrome". No se limitó por edad, idioma, diseño del estudio, ni año de publicación hasta el 31 de diciembre de 2013. Se consultaron las Bases de datos MEDLINE, TripData Base,EMBASE, Google académico.

Elegibilidad de los estudios: se decidió incluir artículos originales, sin importar tamaño de muestra ni periodo de seguimiento, no se limitó por año de publicación, idioma, ni tipo de estudio. Se incluyeron reportes de casos, series retrospectivas y publicaciones en congresos académicos. De los 181 ítems encontrados se analizaron 166 (inglés y humanos), escogiendo las 57 referencias utilizadas por considerarse las de mayor relevancia para el tema a tratar.

\section{Fisiopatología y abordaje diagnóstico del SHUa}

Fisiopatología

Para entender la fisiopatología de esta enfermedad es necesario comenzar por entender el sistema del complemento y su rol en la generación de la enfermedad y sus manifestaciones clínicas.

\section{Sistema del complemento y daño endotelialsubsecuente}

El sistema del complemento es una compleja red de proteínas plasmáticas que hacen parte de la inmunidad innata. Es responsable de la defensa contra los microorganismos mediante funciones de opsonización, quimiotaxis y fagocitosis. El objetivo final del sistema del complemento es la lisis de los microorganismos a través del llamado complejo de ataque a la membrana (CAM). Figura 1.

Los componentes del complemento se producen en el hígado, circulan en el plasma en forma inactiva y son activados por tres vías: vía clásica, vía de la lectina y vía alterna. Describiremos brevemente cada una de ellas, aclarando que es el trastorno en la regulación de la ruta alterna lo que induce la manifestación clínica del SHUa.

La vía clásica del complemento se inicia con el reconocimiento de patógenos o alteraciones en la superficie celular, formándose el complejo antígeno y anticuerpo con la posterior unión de C1q; la vía de la lectina es activada por la unión de los residuos de lectina a los residuos de manosa. Las dos vías convergen en la escisión de $\mathrm{C} 4$, formando $\mathrm{C} 3$ con vertasa $(\mathrm{C} 4 \mathrm{~b} / \mathrm{C} 2 \mathrm{a})$, responsable de la escisión de $\mathrm{C} 3$ a $\mathrm{C} 3 \mathrm{a}$ y $\mathrm{C} 3 \mathrm{~b}$, induciendo la activación de la ruta terminal.

La vía alterna se encuentra activa constantemente por la activación espontánea de $\mathrm{C} 3$, un proceso llamado "tickover". Esto permite que el sistema del complemento sea "activado" y responda rápidamente al trauma e infección. La vía alterna se amplifica rápidamente por las proteínas amplificadoras de complemento, tales como las endotoxinas, inmunoglobulinas (Ig) agregadas y polisacáridos, lo que implica la participación del sistema properdin (factor $\mathrm{B}$ y D, y properdin $\mathrm{P}$ ). En la vía alterna, la C3 convertasa está formada por $\mathrm{C} 3 \mathrm{~b} / \mathrm{Bb}$ y escinde el $\mathrm{C} 3$,resultando en un ciclo de retroalimentación positiva, amplificando la activación del complemento a través de las otras rutas.

Las 3 vías convergen para producir $\mathrm{C} 3 \mathrm{~b}$ y activar la vía final del complemento. C3b desempeña un papel central en el complemento ya que puede recubrir las superficies celulares y funcionar como opsonina en las paredes de los microorganismos. Adicionalmente, se une a la $\mathrm{C} 3$ convertasa para crear la $\mathrm{C} 5$ convertasa $(\mathrm{C} 4 \mathrm{~b} / \mathrm{C} 2 \mathrm{a} / \mathrm{C} 3 \mathrm{~b}$ y $\mathrm{C} 3 \mathrm{~b} / \mathrm{Bb} / \mathrm{C} 3 \mathrm{~b})$, y dividir $\mathrm{C} 5$ en $\mathrm{C} 5 \mathrm{a}$ y $\mathrm{C} 5 \mathrm{~b}$. En este proceso se liberan C3a y C5a que son quimio-tácticos de leucocitos y plaque- 
Figura 1.

Cascada del complemento.

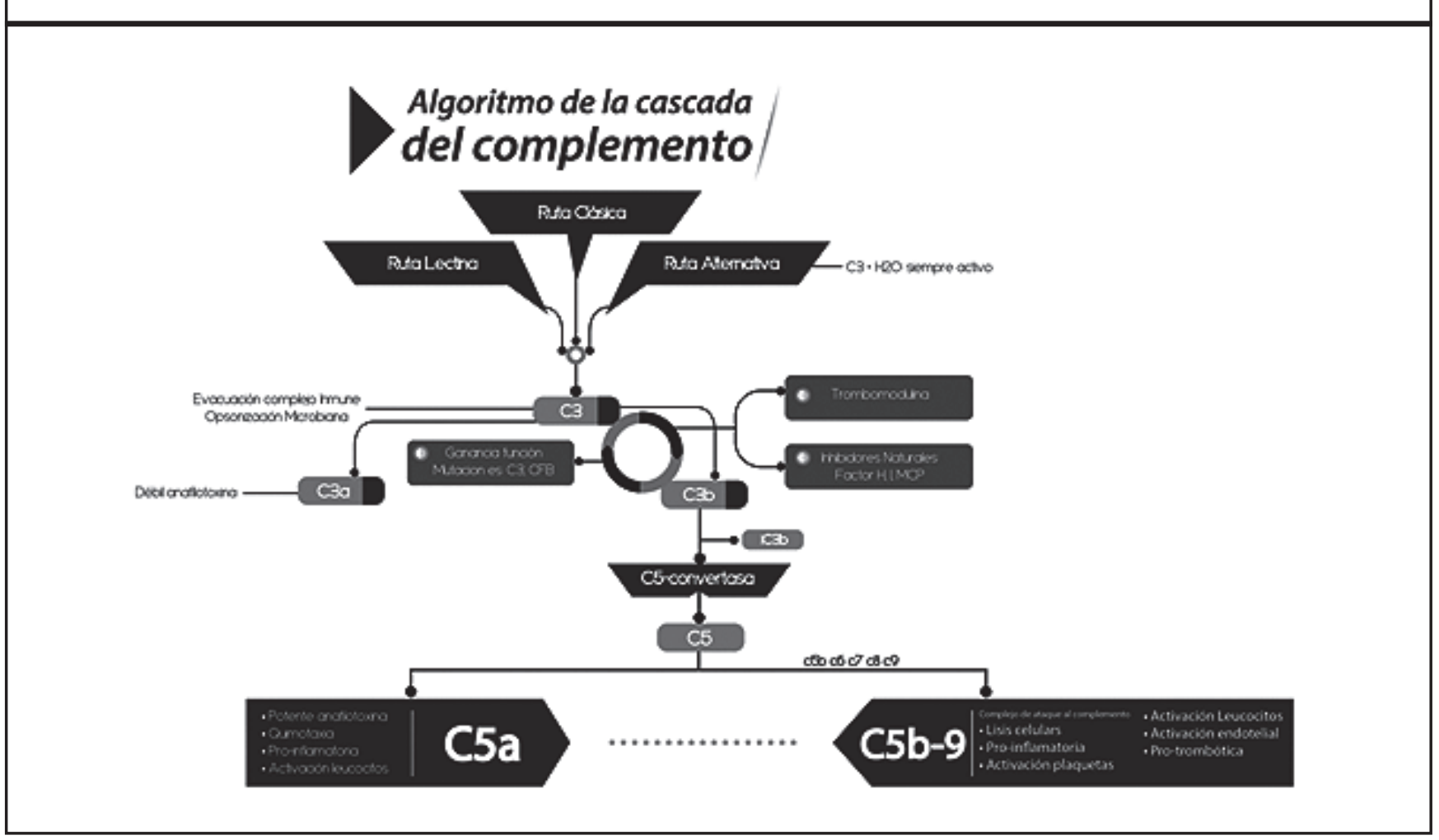

tas, activan la ruta de la coagulación y participan en la activación endotelial. C5b inicia la vía final del complemento uniéndose a C6-C9 para conformar el complejo de ataque a la membrana (CAM) en la superficie de las células objetivo. Finalmente, como se comentó anteriormente, $\mathrm{C} 3 \mathrm{~b}$ puede unirse con el factor B y el cofactor D y producir la C3 convertasa alterna que escinde más $\mathrm{C} 3$ a $\mathrm{C} 3 \mathrm{~b}$, creando una amplificación.

El mecanismo de ensamble del complemento está firmemente controlado por proteínas inhibitorias ubicadas en las membranas de las células huésped, cuyo objetivo es protegerlos de una inadecuada activación celular y su lisis. Esto permite que se logre la homeostasis, con una efectiva destrucción de los organismos extraños previniendo el daño del propio huésped. Los mecanismos reguladores son:

- Factor I (CFI): serina proteasa que realiza la fragmentación de $\mathrm{C} 3 \mathrm{~b}$ transformándolo en $\mathrm{C} 3 \mathrm{~b}$ inactiva.
- Factor $\mathrm{H}(\mathrm{CFH})$ : reconoce $\mathrm{C} 3 \mathrm{~b}$ en la superficie celular a través del extremo C-terminal, es cofactor de la actividad de CFI a través de la región $\mathrm{N}$-terminal y favorece la disociación de C3 convertasa (aceleración del deterioro) a $\mathrm{C} 3 \mathrm{~b} / \mathrm{Bb}$.

- La proteína del cofactor de la membrana (PCM): es una proteína transmembrana que actúa como cofactor del Factor I, el cual realiza la escisión de C3b y C4b depositada en la superficie de la célula huésped. Está compuesta por 4 áreas SCRs Sushi extracelular N-terminal, un dominio transmembrana y una cola citoplasmática C-terminal. Las áreas SCRs Sushi 3 y 4 son responsables de la regulación del complemento ${ }^{4}$.

- La trombomodulina (THBD) es una proteína con función anticoagulante que se encuentra involucrada en la generación del inhibidor (carboxipeptidasa B) de la fibrinólisis mediada por la trombina, la cual escinde C3a y C5a. La THBD se une a 
$\mathrm{C} 3 \mathrm{~b}$ acelerando su inactivación por el Factor I en presencia del factor $\mathrm{H}$.

- El factor de aceleración del deterioro (DAF/ CD55): es una glicoproteína anclada a fosfatidilinositol que previene la formación de $\mathrm{C} 3 \mathrm{~b} / \mathrm{Bb}$ y acelera su destrucción.

- Protectina o CD59: una glicoproteína anclada a fosfatidilinositol la cual previene la unión y polimerización de C5b-C8 a C9 para formar el CAM.

\section{Disregulación del complemento}

El SHUa es una enfermedad del sistema del complemento ${ }^{1}$. La vía alterna siempre está "encendida" y puede auto-amplificar su actividad bajo condiciones de trauma, infecciones y lesión para brindar una respuesta inmune y hematológica inmediata. Adicionalmente, las infecciones gripales, la gestación $\mathrm{u}$ otras condiciones y tratamientos médicos, pueden estimular aún más la actividad del complemento, generando una amplificación significativa del mismo. En los individuos sanos, las células propias se protegen de la actividad y amplificación permanente del complemento a través de un conjunto regulado de inhibidores ${ }^{3,15,16}$. Los pacientes con SHUa carecen intrínsecamente de los reguladores del complemento (activadores e inhibidores de las proteínas) que protegen las células y los tejidos, lo cual induce los efectos crónicos nocivos de un sistema del complemento hiperactivo ${ }^{1,3,14,15}$.

Existen reportes de la actividad anormal del complementoen los pacientes con SHUa y de la amplificación no controlada de manera eficiente como resultado de la pérdida de las proteínas reguladoras del complemento. De hecho, la actividad del complemento es cerca de 4 a 6 veces más alta en los pacientes con $\mathrm{SHUa}^{17,18}$. Esta permanente activación resulta en daño tisular a través de diferentes mecanismos: altera el fenotipo fisiológico tromborresistente de las células endoteliales, aumenta los depósitos de cantidades sublíticas de CAM, aumenta la exocitosis de la P-selectina y la exposición al factor de von Willebrand (vWF), dado que la expresión de los cuerpos deWeibel Palade aumenta durante la activación y daño endotelial, aumenta la expresión del factor tisular, causa la pérdida de la superficie anti- coagulante de los proteoglicanos de heparán sulfato, alterando el citoesqueleto con retracción celular y exposición de la matriz extracelular procoagulante, aumenta la liberación de prostanoides, leucotrienos y citocinas incrementando el reclutamiento de leucocitos y la activación y migración transendotelial.

Los depósitos de C3b y C9 también aumentan en la superficie plaquetaria al igual que CD 40L y P-selectina, los cuales son marcadores de la activación y de la secreción de gránulos, llevando a una activación y agregación plaquetaria prematuras. Si este proceso no se detiene, se convierte en un círculo vicioso que induce daño endotelial y trombosis microvascular secundaria a inflamación y a una continua activación del complemento. Entendiendo el rol del complemento, el SHUa es el prototipo del trastorno de su falta de regulación y la explicación de la diversidad de las manifestaciones clínicas y la agresividad de la misma, así como del componente de enfermedad crónica, con sus implicaciones de morbilidad y mortalidad prematura.

La disregulación de las proteínas del complemento y la consecuente activación del sistema, generan daño celular a nivel endotelial favoreciendo un estado inflamatorio, de agregación plaquetaria y estenosis vascular. Dicha estenosis se manifiesta por la presencia de microtrombos en la microcirculación sistémica. Es importante resaltar que el principal mecanismo de la estenosis vascular en esta entidad es secundario al daño endotelial, que induce los coágulos ricos en fibrina distintivos de los dePTT que son ricos en plaquetas debido a extensos multímeros circulantes de vWF.

\section{Patología}

El término MAT (microangiopatía trombótica) significa un daño histológico de arteriolas y capilares, caracterizado por el engrosamiento e inflamación de la pared vascular, el desprendimiento de las células endoteliales, el alargamiento subendotelial ocasionado por los depósitos de proteínas y el material de la lisis celular y la presencia de trombos plaquetarios que ocluyen los espacios vasculares. No es necesaria una biopsia para el diagnóstico de MAT, esta puede sospecharse por la disminución del recuento plaque- 
tario o trombocitopenia, y la presencia de hemólisis (medida por el aumento de los niveles de LDH o por niveles indetectables de haptoglobina) y la presencia de esquistocitos en el frotis de sangre periférica (FSP). La MAT puede presentarse de forma sistémica y los pacientes con SHUa con frecuencia demuestran una lesión orgánica extra renal.

\section{Presentación clínica}

Los datos referentes a la presentación clínica del SHUa son limitados debido al número de pacientes. Esta patología afecta a niños y adultos, con casos reportados desde el período neonatal. La distribución hombre:mujer es equitativa en la infancia, pero tiende a predominar en las mujeres en la vida adulta. Los eventos infecciosos como las infecciones del tracto respiratorio superior o la gastroenteritis son disparadores de la enfermedad, en aproximadamente la mitad de los pacientes. Aunque la asociación con diarrea se presenta en el SHU-STEC, hasta $24 \%$ de los casos de SHUa presenta antecedentes de diarrea. No está claro si el evento diarreico es un disparador o una consecuencia de la MAT. 21\% de las mujeres presentan su primera manifestación durante la gestación, la mayoría de ellas $(79 \%)$ en el período posparto $^{28}$.

Una historia clínica completa es fundamental, pues los síntomas son inespecíficos: palidez, hiporexia, vómito, fatiga, somnolencia, compromiso de volúmenes urinarios, edemas. Los pacientes pueden presentar hipertensión marcada e inclusive encefalopatía posterior reversible e insuficiencia cardíaca. De hecho, estudios clínicos que involucraron a 67 pacientes han demostrado que $75 \%, 60 \%, 40 \%, 34 \%$ y $46 \%$ de los pacientes tenían síntomas cardiovasculares, gastrointestinales, neurológicos, trombos extra-renales y complicaciones pulmonares, respectivamente ${ }^{50}$.

\section{Paraclínicos}

El SHUa se caracteriza clínicamente por anemia hemolítica microangiopática (descenso de la hemoglobina, lactato deshidrogenasa (LDH) elevada, haptoglobina baja o indetectable, esquistocitos en FSP, prueba coombs negativa), trombocitopenia (plaquetas $<150000$ o una rápida disminución) y lesión renal aguda (hematuria, proteinuria o disminución de la función renal). Hay que tener en cuenta que el SHUa es una enfermedad sistémica que afecta el endotelio de cualquier órgano.

\section{Diagnóstico del SHUa}

\section{Identificación de la MAT.}

El primer paso comienza con la sospecha clínica ante la presentación o antecedentes previos de la MAT. La MAT puede estar definida por parámetros hematológicos, con pruebas diagnósticas que confirmen el consumo plaquetario expresado portrombocitopenia (plaquetas $<150 \times 109 / \mathrm{L}$ ) o la disminución en los recuentos plaquetarios (definida como una disminución $>25 \%$ ). Además, de la activación plaquetaria, se reporta evidencia de hemólisis. Se puede identificar la hemólisis por una elevación de la LDH por encima del límite normal secundario a la fragmentación de glóbulos rojos, la presencia de esquistocitos en el FSP, valores de hemoglobina bajos o niveles de haptoglobina indetectables ${ }^{19}$.

La mayoría de los pacientes con SHUa cursan con una tríada compuesta por:

\section{Hemólisis microangiopática}

2. Alteración plaquetaria

3. Daño de órgano blanco:

- Alteración renal, daño orgánico reconocido con mayor frecuencia en el SHUa: disminución de la tasa de filtración glomerular con o sin alteración del volumen urinario o necesidad de terapia de remplazo renal.

- Anormalidades en el análisis de orina sugestivos de patología glomerular (proteinuria o hematuria).

- Otros síntomas de daño o compromiso orgánico que pueden presentar los pacientes con $\mathrm{SHUa}^{2,12,20}$.

- Neurológicos (20-48\%): convulsiones, desorientación, irritabilidad, diplopía, ceguera cortical, hemiparesia, estupor, coma, entre otros. 
- Gastrointestinales (37\%): diarrea (30\%) y otros síntomas tales como colitis, náusea, vómito o dolor abdominal.

- Cardiovasculares(3-5\%): infarto agudo de miocardio, insuficiencia cardíaca, muerte súbita, HTA y vasculopatía isquémica periférica.

- Insuficiencia de múltiples órganos (5\%): pancreatitis, SNC, hemorragia gastrointestinal, hemorragia alveolar y compromiso hepático.

- Alteraciones de la permeabilidad vascular: ascitis, edema pulmonar, edema cerebral y hemorragia pleural.

\section{Evaluación de causas secundarias de MAT o coexistentes de SHUa}

Existen condiciones específicas que han aumentado la probabilidad de coexistir o manifestarse con SHUa o PTT debido a su activación y amplificación del complemento. El SHUa se identifica normalmente en el contexto de una condición coexistente, como lo evidencia la observación de que aproximadamente el $70 \%$ de los pacientes con SHUa en el Registro Internacional SHUa/PTT fueron identificados con coexistencia de otras enfermedades o condiciones ${ }^{2}$. Las condiciones que frecuentemente coexisten con el SHUa y que pueden enmascararlo son la hipertension arterial maligna, inducido por medicamentos, el LES y el embarazo. La presencia de estas condiciones no descarta el SHUa. La historia de MAT recurrente o la historia familiar deben generar sospecha de SHUa y de trastornos de los reguladores del complemento.

Existen varias condiciones que también pueden presentarse con la MAT, estas incluyen:

- Estado de embarazo o posparto: síndrome HELLP.

- Enfermedades autoinmunes: lupus eritematoso sistémico (LES), síndrome antifosfolípido (SAF) y escleroderma.

- Infección por VIH,H1N1 o neumococo.

- Hipertensión arterial maligna.

- Glomerulopatías.
- Neoplasias.

- Acidemia metilmalónica con homocistinuria.

- Trasplante de médula ósea.

- Medicamentos: quinina, mitomicina C, gemcitabina, cisplatino, radiación con yodo,interferón, clopidogrel, mitomicina, inhibidores de la calcineurina, sirolimus, valaciclovir, contraceptivos orales, inhibidores del factor de crecimiento endotelial vascular (VEGF) y tirosina quinasa (sunitinib, imatinib y dasatinib).

Medicamentos que inducen MAT (trasplante renal): existen ciertas categorías de medicamentos implicadas en el desarrollo de la MAT a través de una toxicidad directa a las células endoteliales ${ }^{21,22}$. Los inhibidores de la calcineurina y algunos agentes quimioterapéuticos pueden inducir activación endotelial y causar MAT auto limitada (MAT inducida por el medicamento) pero también pueden ser el desencadenante de un SHUa de base. Los antecedentes de trasplante y del uso de inhibidores de la calcineurina se encuentran en $24 \%$ de los pacientes con SHUa con condiciones coexistentes ${ }^{2}$. Si con la suspensióndel medicamento no se normaliza la LDH ni el recuento plaquetario, debe considerarse que el paciente tenga una MAT de otro origen y, por lo tanto, alta sospecha de SHUa.

Hipertensión maligna o severa: la hipertensión maligna puede inducir SHUa. Existe evidencia de que la hipertensión maligna o severa puede inducir activación plaquetaria y daño endotelial . Aproximadamente, $30 \%$ de los pacientes con hipertensión maligna presentarán evidencia de $\mathrm{MAT}^{24}$. El Registro Internacional de SHUa/PTT reportó una asociación entre SHUa e hipertensión maligna como una enfermedad coexistente ${ }^{2}$.Se han evidenciado mutaciones de las proteínas del complemento en estos pacientes con hipertensión maligna y coexistencia con $\mathrm{SHUa}^{2}$.

LES: el SHUa puede ser diagnosticado en pacientes con LES ${ }^{2}$.En este, el complemento está activado, induciendo lesión e inflamación celular y generando 
riesgo de desarrollo de MAT. Se ha reportado MAT en $1-4 \%$ de los pacientes con LES. Los reportes de autopsias indican una prevalencia de MAT de $14 \%$ en estos pacientes, lo que sugiere que la MAT se pasa por alto en esta condición ${ }^{25}$. Los pacientes con LES y MAT o ERC estadio 5 tienen un riesgo de muerte 3 a 4 veces mayor que los pacientes con LES sin MAT o insuficiencia renal ${ }^{26}$.

Período posparto o embarazo: el SHUa es causa de MAT en el tercer trimestre de la gestación o en el posparto ${ }^{2}$. El embarazo está asociado con una activación sistémica del complemento para proteger tanto a la madre como al feto de posibles infecciones. De hecho, se ha demostrado que los niveles de las proteínas anafilotoxinas $\mathrm{C} 3 \mathrm{a}, \mathrm{C} 4 \mathrm{a}$ y $\mathrm{C} 5 \mathrm{a}$ son más altos en las mujeres embarazadas que en las no embarazadas, cerca de 2, 4 y 3 veces más, respectivamente $^{26}$. El embarazo precede a la presentación clínica del SHUa en $10 \%$ de las mujeres y puede desenmascarar el SHUa ${ }^{28,29}$. El SHUa relacionado con el embarazo ha sido reportado en el Registro Internacional SHUa/PTT, y se encuentran anormalidades del complemento en $86 \%$ de estas pacientes ${ }^{2}$. El pronóstico es malo, con más de dos tercios de las pacientes llegando a ERC estadio 5, en su mayoría en el mes siguiente al inicio de la manifestación. Adicionalmente, las pacientes embarazadas con una mutación subyacente de los factores reguladores del complemento también pueden presentar síndrome HELLPo preeclampsia severa ${ }^{30}$.

La solicitud de exámenes para evaluar todo lo anterior depende de la sospecha clínica según la información suministrada por el paciente o según su grupo etario.

Diagnóstico de SHUa basado en la exclusión de otras etiologías de MAT

Considerando la similitud del compromiso multisistémico de las MAT, es importante descartar la presencia de PTT y SHU-STEC en el paciente con clínica demi croangiopatía trombótica, para confirmar el diagnóstico de SHUa. En los pacientes con actividad de ADAMST13 $>5 \%$ y prueba STEC ne- gativa debe considerarse la posibilidad de SHUa o microangiopatía trombótica secundaria.

\section{Evaluación de la actividad de ADAMTS-13}

Debido a que las manifestaciones clínicas del SHUa pueden superponerse con las de la púrpura trombocitopénica trombótica (PTT), este debe ser uno de los principales diagnósticos diferenciales. Anteriormente, se consideraba que el diagnóstico de PTT se basaba en la presencia de alteraciones neurológicas, mientras que el diagnóstico de SHUa se basaba en la presencia de compromiso renal. Sin embargo, $47 \%$ de los pacientes con SHUa tienen deterioro neurológico. Por lo tanto, la diferenciación de estas enfermedades no debe basarse únicamente en las manifestaciones clínicas. En este punto es importante la medición de la actividad de ADAMTS-13. El desarrollo de MAT en la PTT se debe a una deficiencia severa de la actividad de ADAMTS-13 (<5-10\%). La disminución severa de la actividad de ADAMTS-13 $<5 \%$ confirma el diagnóstico de PTT y descarta el SHUa. Siempre se debe tomar la prueba en suero antes de iniciar plasmaféresis terapéutica o infusión de plasma (PF/IP) para garantizar una medición precisa de la actividad de ADAMTS-13 ya que el plasma usado en estas terapias tiene ADAMTS-13 y altera los resultados.

En casos en los que la muestra de sangre para evaluar actividad de ADAMTS-13 ha sido tomada después de iniciar la terapia con PF/IP o cuando no hay disponibilidad de la prueba, podría realizarse la aproximación diagnóstica basada en el resultado del recuento plaquetario y creatinina sérica. A este respecto, 4 estudios han sugerido que un nivel de creatinina sérica mayor a $1,69 \mathrm{mg} / \mathrm{dL}$ o un recuento plaquetario mayor a $30 \times 10^{9} /$ Lpodría excluir el diagnóstico de deficiencia severa de ADAMTS-13 ${ }^{31-34}$. De esta manera, las características de los laboratorios pueden diferenciar entre SHUa y deficiencia severa de ADAMTS-13, es decir PTT.

\section{Síndrome hemolítico urémico-STEC}

E1 SHU-STEC es provocado por la Shigatoxina producida por la Escherichiacoli o Shigella dysente- 
riae y debido a que la manifestación de la infección ocasionada por estas bacterias es diarrea, esta enfermedad se conocía anteriormente como SHU-D+ (D, de diarrea). Sin embargo, 30\% de los pacientes con SHUa presentan diarrea, y algunos pacientes con SHU-STEC no la tienen, por lo tanto, esta designación basada en la presencia o ausencia de este síntoma es incorrecta. Lo que orienta el diagnóstico de SHU-STEC es la detección de esta toxina o un cultivo positivo de STEC, por lo que todos los pacientes que presentan síntomas de MAT deben ser tamizados.

La sospecha clínica de SHUa debe ser mayor si el paciente presenta un cuadro de MAT sin diarrea o si presenta diarrea con alguno de los siguientes:

- Menos de 6 meses o más de 5 años de edad.

- SHU recurrente.

- Sospecha de SHU previo.

- MAT anterior no explicada.

- MAT Postrasplante.

- MAT asociado al embarazo (posparto).

- SHU familiar no sincrónico.

- C3 persistentemente bajo.

\section{Recomendaciones acerca del diagnóstico de SHUA}

1. Reconozca tempranamente la presencia de MAT, basado en la clínica y por la presencia de:

a. Anemia hemolítica microangiopática.

b. Trombocitopenia o descenso del recuento plaquetario en un $25 \%$.

c. Lesión de órgano blanco, renal,cardiovascular, neurológico, etc. (Recordar que en el SHUA el daño renal está presente en la mayoría de los casos asociado a alteración en la TFG, requerimiento de terapia de soporte renal opresencia de hematuria o proteinuria en el uroanálisis.

2. Evalué condiciones amplificadoras del complemento como factores desencadenantes (embarazo,LES, trasplante, cáncer, medicamentos, infecciones)

3. Se recomienda, siempre que estén disponibles, realizar pruebas confirmatorias de SHU -STEC (Cultivos, PCR o Elisa) y de PTT (deficiencia de actividad de ADAMTS-13) a todos los pacientes con MAT.

4. En caso de no disponibilidad de realizar la actividad de ADAMTS-13:

a. Sospeche MAT secundariaa deficiencia severa de ADAMTS-13 (actividad menor al 5\%) cuando tenga trombocitopenia severa (menor de 30.000 plaquetas) o compromiso renal no severo (creatinina sérica menor de 1,7 mg/dl).

b. Sospeche MAT por SHUA en el paciente que no hay normalización hematológica o disminución del $25 \%$ de los niveles séricos de creatinina después de 5 sesiones de plasmaféresis.

5. Sospeche siempre SHUA en el paciente que presente:
a. Episodios recurrentes de MAT
b. Antecedente familiar de SHUA
c. Niño menor de 6 meses con MAT
d. Presencia de MAT sinenfermedad diarreica
e. MAT asociadaa complemento bajo especialmente $\mathrm{C} 3$

6. Las pruebas moleculares de detección de anormalidades genéticas de factores del complemento son deseables mas no son indispensables para el diagnóstico de SHUA. 


\section{Algoritmo diagnóstico}

Propuesta del Grupo Colombiano de Consenso para el enfoque del diagnóstico de SHUa

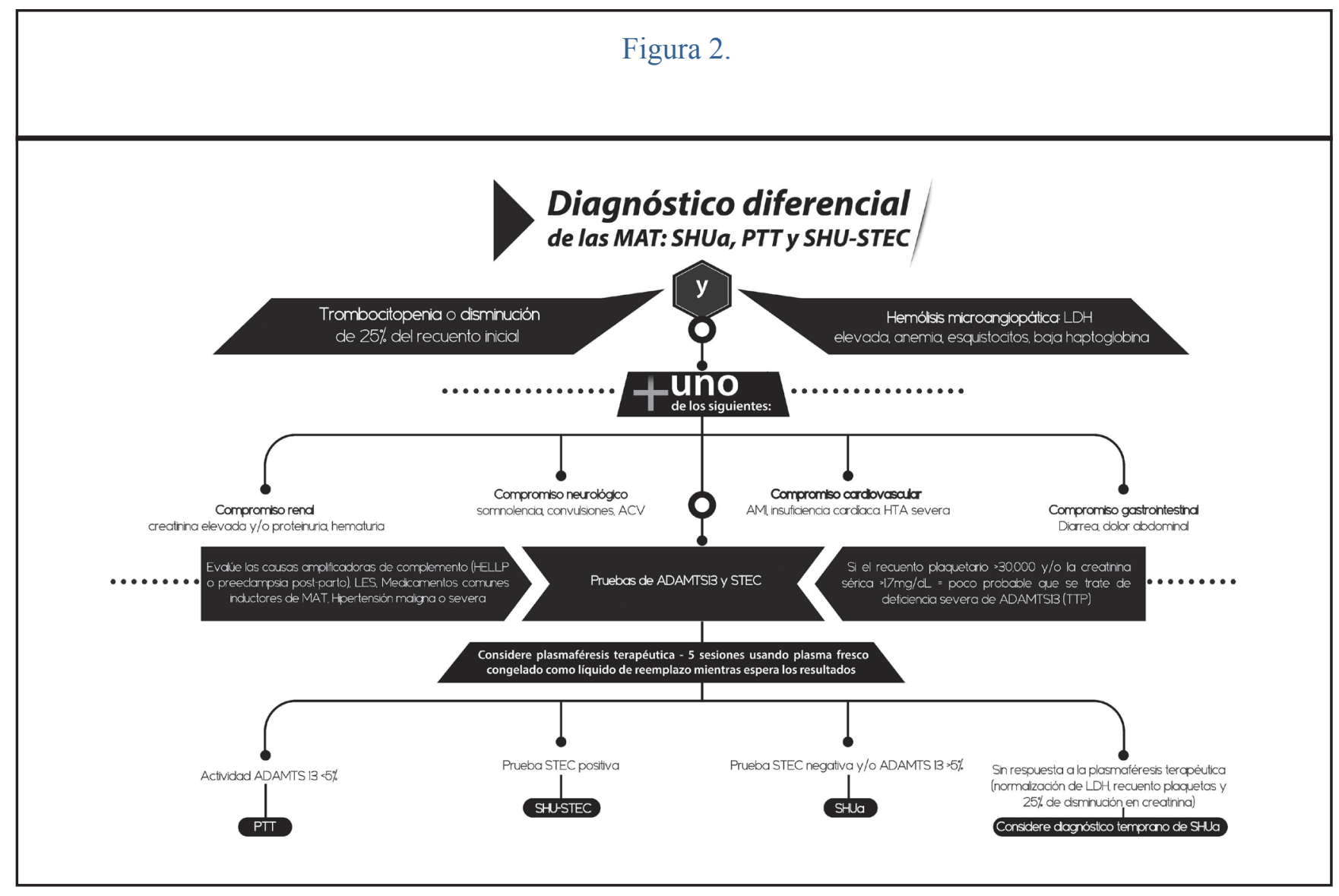

\section{Rol de las pruebas genéticas}

La genética del complemento ha contribuido con nuestro conocimiento sobre el SHUa ${ }^{2}$. Recientes estudios han establecido que, aproximadamente, 40$60 \%$ de los pacientes de SHUa son portadores de mutaciones específicas en los genes del complemento y que estas mutaciones causan la disregulación de la vía alterna del complemento ${ }^{2,35}$. Esta disregulación puede ser producida tanto por una disminución en la actividad de las proteínas reguladoras, como por la actividad anormalmente elevada de C3-convertasas, es decir, mutaciones con ganancia de función y otras con pérdida de función. Las mutaciones descritas a la fecha involucran el factor $\mathrm{H}$ (20-30\%), MCP (5$15 \%)$, factor I (4-10\%), C3 (2-10\%), factor B (1-4\%) yTHBP (3-5\%) y hasta en $12 \%$ de los casos, se ha identificado más de una mutación en el complemento $^{2,34}$. La penetración es incompleta $y$, aproximadamente, $50 \%$ de los portadores de mutaciones factor $\mathrm{H}(\mathrm{CHF})$ o MCP no desarrollan la enfermedad. Las razones no son claras, existen variantes genéticas que influyen sobre este hecho, haplotipos de riesgo no relevantes para la ocurrencia de la enfermedad y disparadores ambientales, tales como la gestación, las infecciones virales, cáncer, trasplante de órganos y ciertos medicamentos ${ }^{34,36}$. 
El primer caso familiar se reportó en gemelos monocigotos en 1965. En 1973 se reportó la disminución de los niveles séricos de $\mathrm{C} 3$ en 5 pacientes con SHU severo. La asociación del SHUa con bajos niveles de CFH en plasma fue reportada por primera vez en 1981; sin embargo, fue solo hasta 1998 cuando Warwickeret al., estudiaron 3 familias con SHUa y establecieron la relación entre el SHUa y el locus que regula la activación del complemento en el cromosoma 1q32 donde se localizan los genes de $\mathrm{CFH}$ yMCP 2,7 ; ellos demostraron una mutación heterocigota en SCR 202. Posteriormente, se han demostrado múltiples mutaciones en losgenes relacionados con CHF (CFHR1, CFHR2, CFHR3, CFHR4, CFHR5) que se encuentran localizados muy cerca y comparten muchas de sus propiedades funcionales. Se han reportado casos de genes híbridos $\mathrm{CFH} /$ CFHR4; estos muestran una actividad normal en su fase líquida pero pierden su función reguladora del complemento en la superficie celular. Los niveles de $\mathrm{C} 3$ se encuentran disminuidos en $30-50 \%$ de los pacientes con mutaciones heterocigotas del $\mathrm{CFH}^{2,7}$.

En 2003, Richards et al., reportaron la primera mutación de MCP, 2 mutaciones en 3 familias, una deleción 6bpy c.822T $>C$, causando esta última un cambio de serina por prolina, induciendo la disminución de la unión de $\mathrm{C}_{3} \mathrm{~b}^{37}$. Posteriormente, se han identificado más de 40 mutaciones diferentes en esta proteína2 las cuales han sido clasificadas como tipo I $(75 \%)$ en las que la expresión en la superficie celular está disminuida, y tipo II (25\%) con una expresión normal, pero con una disminución de la actividad reguladora del complemento ${ }^{7,38}$. En la mayoría de los casos, los niveles de C3 son normales, sin embargo, el registro italiano reportó una disminución del nivel de C3 en 27\% de los pacientes, lo que sugiere que estos pacientes tenían una mutación coexistente que explica la activación del complemento en la fase líquida ${ }^{39}$. Las mutaciones de MCP son más frecuentes en los niños que en los adultos y en los pacientes trasplantados. Esta mutación tiene mejor pronóstico comparada con las otras, contasa de reincidencia postrasplante renal de $20 \%$, atribuyéndose este comportamiento al hecho de que las células del riñón trasplantado no tienen el defecto genético del paciente ${ }^{2,40}$.
Las mutaciones del CFI fueron descritas, por primera vez, en 2004 en 3 pacientes; a la fecha se han descrito más de 40 mutaciones, todas ellas heterocigotas.Estas producen una alteración en la secreción de la proteína o una alteración en la actividad del cofactor que altera la degradación de $\mathrm{C} 3 \mathrm{~b} / 4 \mathrm{~b}$ en la fase líquida y en las superficies celulares. 20-30\% de los pacientes presentan una disminución en las concentraciones séricas de $\mathrm{C} 3$, sus niveles en suero se encuentran disminuidos en una tercera parte de los pacientes. La tasa de reincidencia postrasplante renal ha sido descrita en $45-80 \%$ de los $\operatorname{casos}^{2,7,36}$.

En 2007 y 2009 Goicoechea de Jorge y Roumenina reportaron 4 mutaciones delCFB heterocigotas, estas están asociadas a una ganancia en la función, lo que permite una unión excesiva a $\mathrm{C} 3 \mathrm{~b}$ induciendo una mayor estabilidad y actividad de C3 convertasa. Estas mutaciones se asocian a niveles muy bajos de $\mathrm{C} 3$ y la tasa de reincidencia postrasplante es de $100 \%{ }^{2}$.

C3 es la piedra angular del sistema del complemento, las primeras mutaciones reportadas se localizan en las cadenas alfa y beta; en 2008, Frémeaux-Bacchi reportó 9 mutaciones de $\mathrm{C} 3$ en 14 pacientes de 11 familias, incluyendo una mutación p-R570W.Algunas disminuyen la capacidad de $\mathrm{C} 3$ para unirse a $\mathrm{MCP}$, generando una convertasa mutante resistente a la escisión por CFI. Al igual que en los otros factores, se están descubriendo diferentes mutaciones de esta proteína ${ }^{2,7}$. Los niveles de C3 en plasma son bajos en $70-80 \%$ de los pacientes y el riesgo de recurrencia postrasplante es de $40-70 \%{ }^{2}$.

Las mutaciones de THBDson las que se han descrito más recientemente; se demostraron en una cohorte italiana de 13 pacientes. La THBD se une al C3b y al CFH y acelera la inactivación de C3b por CFI. En casos de mutación, su capacidad de descomponer $\mathrm{C} 3 \mathrm{~b}$ se encuentra disminuida. Los niveles de C3 están bajos en la mitad de los pacientes y no se ha determinado el riesgo de recurrencia postrasplante ${ }^{34,41}$.

Las alteraciones funcionales adquiridas delCFH debido a anticuerpos dirigidos contra la región C-terminalfueron descritas en el 2006. Las IgGcontra el CFH SCR19 y 20 inhiben la unión del CHF a C3b $\mathrm{y}$ aumentan las concentraciones en las superficies celulares $^{2,37} \cdot 90 \%$ de los pacientes con anticuerpos 
anti-CFH tienen deficiencia absoluta de CFHR1 y CFHR3, lo que sugiere que esta deleción desempeña un rol patogénico en el desarrollo de estos anticuerpos. Los pacientes también pueden presentar mutaciones en otros componentes del complemento y en el 40-60\% de los casos presentan disminución en los niveles de C3. Se han descrito hasta en $10 \%$ de los casos de $\mathrm{SHUa}^{2}$.

$10-12 \%$ de los pacientes presentan mutaciones en más de un componente genético; esto significa que la coincidencia de diferentes factores genéticos es determinante para el desarrollo del SHUa (teoría de múltiples hits) ${ }^{37}$.

Dada la extensa variedad de mutaciones y la incompleta penetración de las mismas, los síntomas y la edad de inicio son diferentes, inclusive dentro de la misma familia, y calcular el riesgo de la enfermedad en personas cuyos familiares sufren de SHUaes, hasta el momento, de gran dificultad. En la cohorte pediátrica de Francia se observó una edad de inicio temprano en los pacientes con mutaciones del $\mathrm{CFH}$ (promedio 6 meses, 3 días a 3.6 años) y del CFI (promedio 2 meses, 1 día a 3.8 años), mientras que el inicio en niños mayores de 1 año fue más frecuente en los casos de mutaciones de la MCP2. Los anticuerpos anti CHF son más frecuentes entre los 7 y los 11 años 2,7 .

Se debe realizar una medición de los niveles en suero y la secuencia genética en laboratorios de referencia experimentados en este proceso (Tabla 1).Las muestras de sangre deben tomarse antes de iniciar el tratamiento con PF/IP, exceptuando la expresión deMCP en los leucocitos periféricos, la cual no se ve afectada por esta terapia. En el caso de las mutaciones homocigotas, todos los pacientes presentan disminución de todos los niveles de factor $\mathrm{H}(<1 \%$ -normal 70-130\%), C3 (<40-170mg/dL - normal $660-1250 \mathrm{mg} / \mathrm{dL})$, factor B $(17-70 \mathrm{mg} / \mathrm{L}$ - normal 90 $320 \mathrm{mg} / \mathrm{L})$, y CH50 (<10-24\%- normal 70-130).En pacientes con mutaciones heterocigotas se pueden encontrar niveles bajos o normales, por ejemplofactor H (30-55\%), C3 (240 a $834 \mathrm{mg} / \mathrm{dL})$, factor B (55 a $250 \mathrm{mg} / \mathrm{L})$, y CH50 (59 a $124 \%)^{42}$.

En todos los pacientes con sospecha clínica de SHUa se deben medir los niveles de $\mathrm{C} 3$ y $\mathrm{C} 4$ en suero.

Más del $70 \%$ de los pacientes con mutaciones del $\mathrm{CFH}, \mathrm{CFI}, \mathrm{C} 3$ o THBDo con anticuerpos anti CFH desarrollan ERCo mueren con el primer episodio o dentro de los 3 años después de su manifestación. Los pacientes con mutaciones de la MCP tienen más reincidencias; sin embargo, tienen un mejor pronóstico a 3 años que todos los otros grupos ${ }^{6}$. La mortalidad es mayor en niños que en adultos $(6.7 \%$ vs. $0.8 \%$ a 1 año $\mathrm{p}=0.02$ ) pero la progresión a ERC después del primer episodio es más frecuente en los adultos $(46 \% \text { vs. } 16 \% \mathrm{p}<0.001)^{34}$.

Las pruebas genéticas y las pruebas del complemento en suero no son indispensables para hacer el diagnóstico de SHUa. La razón de esto es que, aproximadamente, $30 \%$ a $50 \%$ de los pacientes de $\mathrm{SHUa}$

\begin{tabular}{|ll|}
\hline \multicolumn{2}{|c|}{ Tabla 1. } \\
\hline \multicolumn{2}{|c|}{ Técnicas de medición de los componentes del complemento } \\
\hline Prueba diagnóstica & Téenica \\
\hline Niveles de C3 y C4 en suero & Nefelometría \\
Niveles de C3d en suero & Inmunoelectroforesis (EDTA) \\
CFH y CFI en suero & Inmunodifusión radial \\
Anticuerpos anti-CFH & ELISA (suero) \\
Expresión de PCM & FACS (EDTA) \\
Tamizaje de CFH, CFI, MCP, C3 y CFB & Análisis de secuencia (EDTA) \\
\hline Adaptado de Ref ${ }^{39}$. & \\
\hline
\end{tabular}


no presentan una mutación identificable. Aunque los defectos genéticos en las proteínas reguladoras de la vía alterna del complemento son una causa directa de SHUa, el algoritmo diagnóstico actual no requiere de las pruebas genéticascomo confirmación SHUa.

\section{Enfoque de la clasificación genética en el SHUa}

Es importante tener en cuenta que la identificación de la mutación genética no solo se puede relacionar con la causa del SHUa sino también es considerada un factor de riesgo de la enfermedad. El rol específico en la determinación de cada una de las anormalidades del complemento mediante la secuenciación sigue siendo incierto; sin embargo, con la información actual, en aquellos pacientes con SHUa en los cuales se han identificado mutaciones del complemento, se puede reafirmar el diagnóstico, brindar consejería genética a los familiares de quienes padecen esta enfermedad, predecir el riesgo de reincidencia,evaluar el pronóstico en términos de sobrevida renal y mortalidad general,evaluar el curso postrasplante renal, determinar potencialmente la duración del tratamiento y qué tratamiento escoger para prevenir las recaídas postrasplante (tabla 2$)^{2}$.
También desempeña un rol significativo en la selección del donante vivo relacionado.

\section{Recomendaciones acerca del estudio genético} en SHUa

El tamizaje para mutaciones de todos los genes relacionados conSHUa; CFH,CFI,MCP,C3,CFB, yTHBD, debe ser obligatorio en las pruebas previas al trasplante renal. En el resto de casos es deseable pero no obligatoria. La medición de los niveles en suero y la secuencia genética se debe realizar en laboratorios de referencia experimentados en este proceso.

\section{Tratamiento}

Durante muchos años la plasmaféresis (PF)fue la única alternativa terapéutica para esta enfermedad; sin embargo, los resultados a 5-10 años siguen siendo desfavorables con tasas muy altas de progresión a ERC y mortalidad (60-80\%) ${ }^{2}$. Desde el 2011, el eculizumab se encuentra disponible, este es un anticuerpo monoclonal recombinante híbrido Ig2/Ig4, totalmente humanizado, dirigido contra el componente C5 del complemento humano. Ha sido diseñado para minimizar la inmunogenicidad, el reclutamiento de las células inflamatorias y la activación del comple-

\section{Tabla 2.}

\begin{tabular}{|c|c|c|c|c|c|c|c|}
\hline \multicolumn{8}{|c|}{ Características clínicas de los pacientes de SHU a según las mutaciones genéticas. } \\
\hline \multirow[t]{2}{*}{ Gen } & \multirow[t]{2}{*}{ Frecuencia } & \multicolumn{2}{|c|}{ Edad mínima de inicio } & \multirow{2}{*}{$\begin{array}{l}\text { Riesgo de } \\
\text { muerte o CK } \\
5 \text { a 1año }\end{array}$} & \multirow{2}{*}{$\begin{array}{l}\text { Riesgo de } \\
\text { reincidencia } \\
\text { postrasplante }\end{array}$} & \multirow{2}{*}{$\begin{array}{l}\text { Riesgo de } \\
\text { recaída }\end{array}$} & \multirow{2}{*}{$\begin{array}{l}\text { Indicación de } \\
\text { plasmaféresis }\end{array}$} \\
\hline & & Niños & Adultos & & & & \\
\hline $\mathrm{CFH}$ & $20-30 \%$ & $\mathrm{RN}$ & Cualquiera & $50-70 \%$ & $50 \%$ & $75-90 \%$ & Sí \\
\hline CFI & $4-10 \%$ & $\mathrm{RN}$ & Cualquiera & $50 \%$ & $10-30 \%$ & $45-80 \%$ & Sí \\
\hline $\mathrm{MCP}$ & $5-15 \%$ & $>1$ año & Cualquiera & $0-6 \%$ & $70-90 \%$ & $<20 \%$ & cuestionable \\
\hline $\mathrm{C} 3$ & $2-10 \%$ & $7 \mathrm{~m}$ & Cualquiera & $60 \%$ & $50 \%$ & $40-70 \%$ & Sí \\
\hline CFB & $1-4 \%$ & $1 \mathrm{~m}$ & Cualquiera & $50 \%$ & $100 \%$ & Cualquiera & \\
\hline THBD & $3-5 \%$ & $6 \mathrm{~m}$ & Rara & $50 \%$ & $30 \%$ & $1 \mathrm{p}$ & Sí \\
\hline Anti CFH & $6 \%$ & 7-11años & Cualquiera & $30-40 \%$ & $40-60 \%$ & Altos títulos & Sí (+inmunosupresor) \\
\hline
\end{tabular}


mento $^{39,43}$. La concentración normal de C5 en plasma es de aproximadamente $70 \mu \mathrm{g} / \mathrm{ml}$; el eculizumab logra el bloqueo total del complemento cuando su concentración en suero llega a $35 \mu \mathrm{g} / \mathrm{ml}$.Después de la administración endovenosa, eleculizumab tiene una vida media de aproximadamente $11 \pm 3$ días, y se distribuye en el espacio vascular.

\section{Terapia de soporte: plasmaféresis terapéutica/ intercambio plasmático (PF/IP)}

Históricamente la PF/IPha sido empíricamente la alternativa terapéutica para el SHUa, esto después de observar hace más de 3 décadas queeste tratamiento disminuía las tasas de mortalidad en una población de pacientes con SHU-PTT ${ }^{1}$. La evidencia sustenta que el remplazo de ADAMTS-13 con PF/IP podría mejorar los resultados en los pacientes de $\mathrm{PTT}^{44}$. Sin embargo, el papel de PF/IPen el SHUaes menos claro. Evidencia reciente sugiere que la PF/IPes inefectiva para controlar de manera adecuada la activación sistémica y permanente del complemento en pacientes con $\mathrm{SHUa}^{17,45}$. Esto se reflejaen que los pacientes que han recibido exclusivamente tratamiento conPF/IP progresan, con cierta frecuencia, a cuadros clínicos deERC, complicaciones extra-renales o muerte ${ }^{13,46}$, es así como 9-15\% de los pacientes muere y $33 \%$ progresan a insuficiencia renal dentro del primer año de la manifestación clínica de MATa pesar del manejo de mantenimiento con PF/IP en el lapso de 1 año ${ }^{2,7,47}$.

Adicionalmente, es conocido que las sesiones de PF/ IP reportan como complicaciones técnicas los sangrados, trastornos electrolíticos, procesos infecciosos y las relacionadas con los accesos vasculares; siendo estas más importantes en la población pediátrica $^{1,46}$. Sin embargo, a pesar de la incapacidad de la PF/IPpara el tratamiento y manejo del SHUa, tradicionalmente la PF/IP ha sido parte de la primera línea intervencionista, especialmente en instancias en las cuales no hay disponibilidad de eculizumab oel diagnóstico no es claro, considerándose quela PF/IPpuede dar apoyo provisional a los pacientes de SHUa en espera de confirmación clínica o paraclínica.

\section{Eficacia y seguridad de eculizumab en el manejo de pacientes con diagnóstico de SHUa}

Se han reportado 4 estudios clínicos de eculizumab realizados por la industria, en pacientes con SHUa, los 2 estudios de registro C08-002 y C08-003 y 2 estudios en curso, C10-003 y C10-00,46,45,48-52 . Adicionalmente a estos estudios se realizó un estudio clínico retrospectivo (C09-001r) $)^{6,12,53}$. Los participantes del estudio eran todos negativos a la toxina Shiga y tenían una actividad de ADAMTS-13 superior a $5 \%{ }^{6,45}$. No se exigió un tamizaje previo o la identificación de una mutación genética del complemento en los participantes del estudio ${ }^{6,45}$. A continuación presentamos un resumen sobre la eficacia y seguridad clínica del eculizumab en los estudios clínicos prospectivos (tablas 3 y 4).

\section{Estudios prospectivos: C08-002 C08-003}

E1 estudio C08-002, evaluó la seguridad y eficacia de eculizumab en 17 pacientes (adultos y adolescentes) con enfermedad activa progresiva o tratamiento con $\mathrm{PF} / \mathrm{IP}^{6,45}, 54$. Se evaluó como desenlace primariola disminución de la MAT medida por el cambio en el recuento plaquetario. No se requería la identificación previa de alguna mutación del complemento $^{6,45,54}$. Los recuentos plaquetarios se normalizan a las 26 semanas en 14 de 17 pacientes $(82 \%)$ y la normalización hematológica en 13 pacientes $(76 \%)$ en el mismo periodo de observación, incrementándose a $88 \%$ de los pacientes a los 2 y 3 años de seguimiento (tablas 3 y 4) $)^{6,45,51}$. En este estudio, 4 de los 5 pacientes que venían en diálisis recuperaron la función renal $\mathrm{y}$, por lo tanto, la dependencia de diálisis. $88 \%$ de los pacientes no volvieron a requerir $\mathrm{PF} / \mathrm{IPdurante}$ todo el periodo de estudio ${ }^{45}$. Se observó una mejoría en la TFGe $\left(\geq 15 \mathrm{~mL} / \mathrm{min} / 1.73 \mathrm{~m}^{2}\right)$ en $47 \%$ de los pacientes (8/17) a las 26 semanas y en $59 \%(10 / 17)$ a los 2 y 3 años de seguimiento $45,51,54$. Sesenta y cinco por ciento de los pacientes $(11 / 17)$ demostraron una disminución mayor al $25 \%$ en los valores de creatininaplasmática hacia la semana 26 , porcentaje de pacientes queaumentó a $76 \%$ a los 2 y 3 años de seguimiento. Por último, la calidad de 
vida mejoró con el tratamiento con eculizumab, el cambio en EQ-5Dfue muy significativo a las 26 semanas y se mantuvo igual para el segundo y tercer año de seguimiento ${ }^{45,51,54}$. El cambio en el recuento plaquetario, la normalización hematológica y la estabilización o mejoría renal, con el tratamiento con eculizumab, se alcanzaron independientemente de la identificación de una mutación del complemento o de antecedentes de trasplante renal ${ }^{6,45,54}$.

En el estudio C08-003, un total de 20 pacientes con enfermedad prolongada e insuficiencia renal crónica que habían recibido PF/IP, a largo plazo, fueron tratados con eculizumab durante 26 semanas con la opción de inscribirse en un estudio de extensión (total 3 años) $)^{6,45,54}$. A las 26 semanas, $80 \%$ de los pacientes estaban libres de eventos de MAT (sin disminución del recuento plaquetario $>25 \%$, sin PF/IPy sin iniciar diálisis $)^{45,54}$. Como se muestra en lastablas 1 y 2 , un total de 18 de 20 pacientes (90\%)lograron normalización hematológica a la semana 26 , la cual se mantuvo en el seguimiento a 3 años, ${ }^{47}$. El tratamiento indefinido con eculizumab resultó en un aumento continuo y sostenido en la TFGe. Los pacientes siguieron mejorando la función renal durante el seguimiento, ya que $5 \%$ de los pacientes a las 26 semanas, $15 \%$ a las 62 semanas y $40 \%$ de los pacientes a las semanas 114 y 156 lograron un cambio en la TFGe $\geq 15 \mathrm{ml} / \mathrm{min} / 1.73 \mathrm{~m}^{2}$ 45,47,54. Todos los pacientes en tratamiento con eculizumab en este estudio suspendieron el tratamiento con $\mathrm{PF} /$ IPy no volvieron a requerir diálisis ${ }^{6,45}$. Los pacientes tuvieron una mejoría clínicamente significativa en la calidad de vida (QoL), medida por EuroQoL-5D a la semana 26,la cual se mantuvo hasta el final del estudio $^{45,47}$.El cambio en el recuento plaquetario, la normalización hematológica y la estabilización o mejoría renal con el tratamiento con eculizumab se lograron independientemente de la identificación de una mutación del complemento o de antecedentes de trasplante renal ${ }^{6,45}$. Un paciente fallece, sin ser atribuido al tratamiento con eculizumab ${ }^{47}$.

Estos 2 estudios clínicos demuestran que el tratamiento con eculizumab a largo plazo es efectivo en pacientes con SHUa ${ }^{54}$. Igualmente se encontró asociación estadísticamente significativa $(\mathrm{p}<0.05)$ entre el tiempo de inicio del tratamiento con eculizumab y mejores desenlaces renales medidos por incremento en TFG. Estos hallazgos podrían sugerir, que es importante definir tempranamente el inicio de este tratamiento en los casos con SHUa con el fin de alcanzar mejores desenlaces clínicos.

\section{Estudio prospectivo C10-003}

Este es el primer estudio prospectivo que evaluó el tratamiento en una población pediátrica de SHUa. Los pacientes no necesitaban recibir PF/IP antes del inicio de eculizumab, como criterio de inclusión. Se evaluó la eficacia de eculizumab en 22 pacientes pediátricos. Se definió respuesta completa como la normalización de los niveles de plaquetas y LDH y la disminución $\geq 25 \%$ del valor inicial de la creatinina sérica tomada en 2 mediciones consecutivas (más de 4 semanas de diferencia $)^{6,48}$. La respuesta completa se documentó en 14 de 22 pacientes (64\%) a las 26 semanas (tabla 3$)^{48}$. El 95\% alcanza la normalización plaquetaria y el $82 \%$ la hematológica ${ }^{48}$. El $73 \%$ presentó una disminución de creatinina sérica $\geq 25 \%$ a lo largo de 26 semanas de tratamiento y el $86 \%$ de los pacientestuvo mejoría en la TFGea valores por encimade $15 \mathrm{~mL} / \mathrm{min} / 1.73 \mathrm{~m}^{2}{ }^{48}$. Por último, 9 de los 11 pacientes $(82 \%)$ en terapia de remplazo renal suspendieron la diálisis con el tratamiento con eculizumab $^{6,48}$. Los10 pacientes que estaban en tratamiento conPF/IP al inicio del estudio, la suspendieron. Este estudio aún se encuentra en curso ${ }^{6}$.

\section{Estudio prospectivo C10-004}

El estudio C10-04 es un estudio clínico en curso, diseñado para evaluar la eficacia de eculizumab, en 41 pacientes adultos con SHUa. La respuesta completa a la MATse definió como la normalización en los niveles de plaquetas y LDH y una disminución $>25 \%$ desde el valor inicial en creatinina sérica, en 2 mediciones consecutivas (más de 4 semanas de diferencia). Los pacientes no necesitaban recibir PF/IP antes del inicio de eculizumab. La normalización plaquetaria fue lograda por $98 \%$ de los pacientesy la normalización hematológica por $88 \% 53.73 \%$ de los pacientes logró una respuesta completa a MATa lo largo de 26 semanas $^{53}$. Veintidós de 41 pacientes 


\section{Tabla 3.}

Características iniciales de los estudios clínicos prospectivos de eculizumab y datos de eficacia a las 26 semanas ${ }^{6,45,48,53,54}$.

\begin{tabular}{|c|c|c|c|c|}
\hline Características & $\begin{array}{l}\mathrm{C} 08-002(\mathrm{~N}=17) \\
\text { MAT activa } \\
\text { progresiva }\end{array}$ & $\begin{array}{l}\text { C08-003 }(\mathrm{N}=20) \\
\text { SHUa prolongado }\end{array}$ & $\begin{array}{l}\mathrm{C} 10-003(\mathrm{~N}=22) \\
\text { Pediátrico } \\
\text { prospectivo }\end{array}$ & $\begin{array}{l}\text { C10-004 }(\mathrm{N}=41) \\
\text { Adultos } \\
\text { prospectivo }\end{array}$ \\
\hline \multicolumn{5}{|c|}{ Características iniciales } \\
\hline Edad; años (mediana; rango) & $28(17-68)$ & $28(13-63)$ & $6.6(6.1) \mathrm{a}$ & $40.3(15.3) \mathrm{a}$ \\
\hline Hombres; n (\%) & $5(29)$ & $8(40)$ & $12(55)$ & $13(32)$ \\
\hline $\begin{array}{l}\text { Mutación del complemento o auto } \\
\text { anticuerpos; } \mathrm{n}(\%)\end{array}$ & $13(76)$ & $14(70)$ & $11(50)$ & $21(51)$ \\
\hline $\begin{array}{l}\text { Tiempo desde el diagnóstico al tamizaje; } \\
\text { meses (mediana; rango) }\end{array}$ & $9.7(0.3-235.9)$ & $48.3(0.7-285.8)$ & $0.56(0.03-191.3)$ & $0.8(0-311)$ \\
\hline PF/IP; n(\%) & $17(100)$ & $20(100)$ & $10(45)$ & $35(85)$ \\
\hline Diálisis; n(\%) & $6(35) \mathrm{b}$ & $2(10)$ & $11(50)$ & $24(59)$ \\
\hline Trasplante renal previo; $\mathrm{n}(\%)$ & $7(41)$ & $8(40)$ & $2(9)$ & $9(22)$ \\
\hline Plaquetas<150x109/L; n(\%) & $15(88)$ & $3(15)$ & $22(100)$ & $27(66)$ \\
\hline LDH>ULN; $n(\%)$ & $10(59)$ & $4(20)$ & $19(86)$ & $32(78)$ \\
\hline $\mathrm{TFGe} \leq 60 \mathrm{ml} / \mathrm{min} / 1.73 \mathrm{~m} 2 ; \mathrm{n}(\%)$ & $17(100)$ & $18(90)$ & $18(82)$ & $41(100)$ \\
\hline \multicolumn{5}{|c|}{ Criterios de eficacia a las 26 semanas de tratamiento con eculizumab } \\
\hline Respuesta completa a MAT; n(\%) & $11(65)$ & $5(25)$ & $14(64)$ & $30(73)$ \\
\hline Estado libre de eventos de TME; \% & 88 & 80 & NR & NR \\
\hline Normalización plaquetaria; n(\%) & $14(82)$ & NA & $21(95)$ & $40(98)$ \\
\hline Normalización hematológica; n(\%) & $13(76)$ & $18(90)$ & $18(82)$ & $36(88)$ \\
\hline $\begin{array}{l}\text { Aumento en la } \mathrm{TFGe} \geq 15 \mathrm{ml} / \mathrm{min} / 1.73 \mathrm{~m} 2 \\
\mathrm{n}(\%)\end{array}$ & $8(47)$ & $1(5)$ & $19(86)$ & $22(54)$ \\
\hline $\begin{array}{l}\text { Disminución en creatinina sérica } \geq 25 \% \text {; } \\
\% \text { (IC } 95 \% \text { ) }\end{array}$ & $11(65)$ & $3(15)$ & $16(73)$ & NR \\
\hline $\begin{array}{l}\text { Cambio promedio en HRQL en puntaje } \\
\text { EQ-5D (IC 95\%) }\end{array}$ & $\begin{array}{l}0.32 \\
(0.24-0.39 ; \mathrm{P}<0.001)\end{array}$ & $\begin{array}{l}0.10 \\
(0.05-0.15 ; \mathrm{P}<0.001)\end{array}$ & NR & NR \\
\hline \multicolumn{5}{|c|}{$\begin{array}{l}\text { Abreviaturas: DE: Desviación estándar; NR: No reportado; ULN: Límite normal superior; MAT: Microangiopatía trombótica; NA: No } \\
\text { aplicable; HRQL: Calidad de vida relacionada con la salud. }\end{array}$} \\
\hline
\end{tabular}




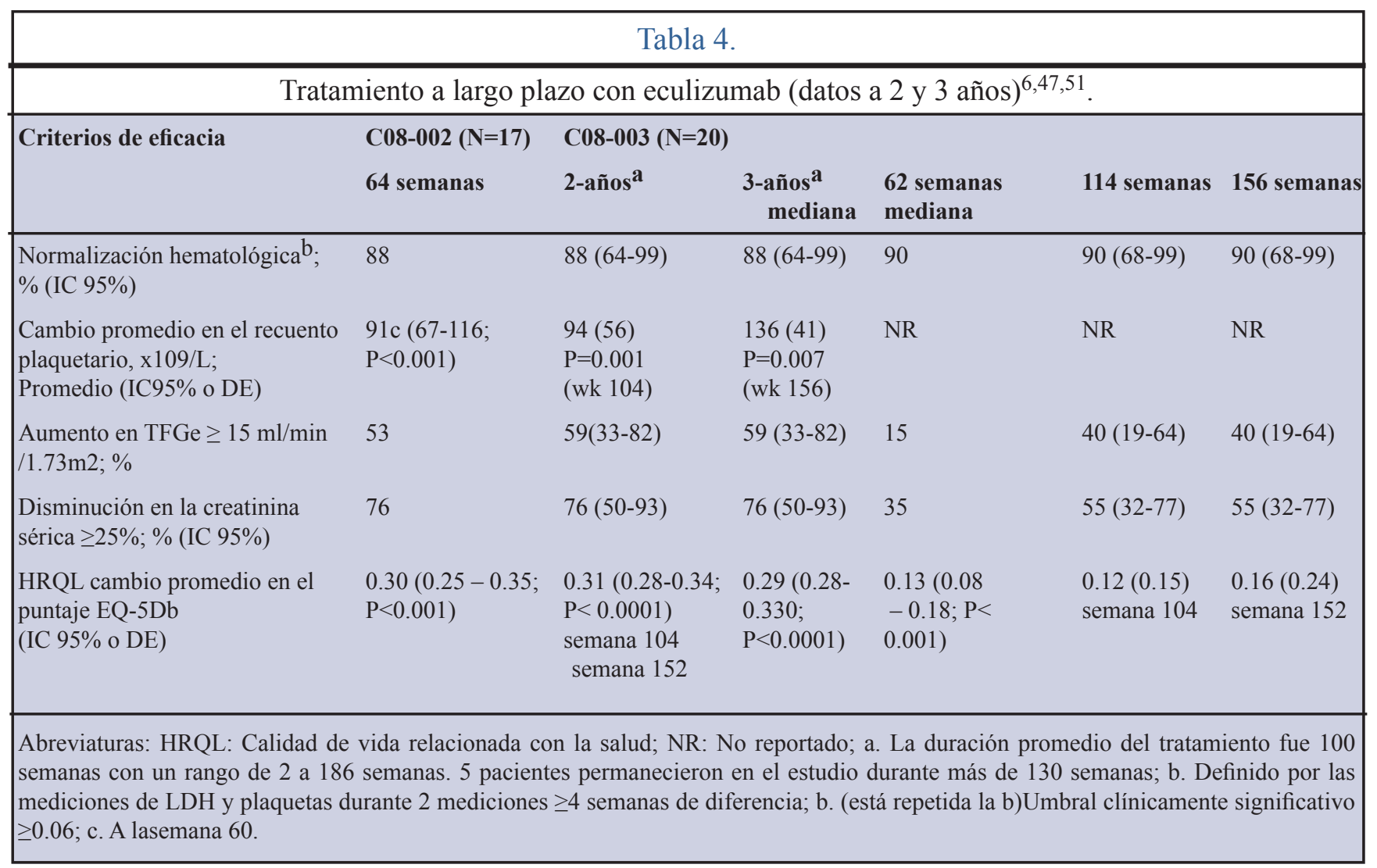

(54\%) lograron una mejoría en la TFGe,desde el valor inicial, a lo largo de 26 semanas. La diálisis se interrumpió en $83 \%$ de los pacientes que estaban en este procedimiento al inicio ${ }^{53}$.

\section{Medidas para eliminar el riesgo de infecciones con Neisseria meningitidis}

Los pacientes con deficiencia severa de C5 o, por lo tanto, con un bloqueo total con medicamentos como eculizumab, se encuentran en mayor riesgo de infecciones por Neisseria meningitidis ${ }^{57}$.Por lo tanto, todos los pacientes con SHU deben ser vacunados contra estabacteria antes de que reciban la primera dosis. La vacuna se debe administrar lo más pronto posible en el curso de la enfermedad para optimizar su eficacia. Se deben utilizar vacunas tetravalentes (A, C, Y, W135), de preferencia conjugadas.Los pacientes en los que se inicia el eculizumab antes de 2 semanas de haberse vacunado, deben recibir antibió- ticos profilácticos diariamente (p.ej.penicilina oral) hasta 2 semanas después de la vacuna ${ }^{56,57}$. Se debe administrar un macrólido a los pacientes alérgicos a la penicilina. Hay que tener en cuenta que las vacunas, actualmente disponibles, no cubren todas las cepas de $N$. Meningitidis incluyendo el serogrupo de mayor prevalencia en Europa y América, es decir, el serogrupo B. Adicionalmente, una gran incertidumbre rodea la eficacia de las vacunas en los pacientes inmunocomprometidos (p.ej. aquellos con enfermedad renal en etapa terminal y pacientes con trasplante renal). Estas preocupaciones han hecho que algunos países, incluyendo Francia, exijan profilaxis permanente con antibióticos a lo largo del tratamiento con eculizumab. Los pacientes deber ser revacunados de acuerdo con las guías médicas vigentes. Es importante anotar que también se necesitan vacunas contra la infección porHaemophilus influenzae tipo B y Streptococcus pneumoniae en los niños tratados con eculizumab ${ }^{56,57}$. 


\section{Régimen de dosis recomendado - SHUa}

Para pacientes $>18$ años de edad, la terapia con eculizumab consiste en ${ }^{56}$ :

- $900 \mathrm{mg}$ semanalmentedurante las primeras 4 semanas, seguido de
- 1200 mg en la quinta semana y luego,

- 1200 mg cada 2 semanas de ahí en adelante.

Para pacientes $<18$ años de edad, administre eculizumab con base en el peso corporal según la siguiente recomendación (tabla 2$)^{56}$

\begin{tabular}{|lll|}
\hline Peso del paciente & Inducción & Mantenimiento \\
\hline $40 \mathrm{~kg}$ y más & $900 \mathrm{mg}$ a la semanax 4 dosis & $1200 \mathrm{mg}$ a la semana 5;luego 1200 mg cada 2semanas \\
$30 \mathrm{kga}$ menos de $40 \mathrm{~kg}$ & $600 \mathrm{mg}$ a la semana x 2 dosis & $900 \mathrm{mg}$ a la semana 3;luego 900 mg cada 2 semanas \\
$20 \mathrm{~kg}$ a menos de $30 \mathrm{~kg}$ & $600 \mathrm{mg}$ a la semana x 2 dosis & $600 \mathrm{mg}$ a la semana 3;luego 600 mg cada 2 semanas \\
$10 \mathrm{~kg}$ a menos de $20 \mathrm{~kg}$ & $600 \mathrm{mg}$ a lasemana x 1 dosis & $300 \mathrm{mg}$ a la semana 2;luego 300 mg cada 2 semanas \\
$5 \mathrm{~kg}$ a menos de $10 \mathrm{~kg}$ & $300 \mathrm{mg}$ a la semana x 1 dosis & $300 \mathrm{mg}$ a la semana 2;luego 300 mg cada3 semanas \\
\hline
\end{tabular}

\section{Recomendaciones acerca del tratamiento en pacientes con SHUA}

1. Se recomienda la utilización de eculizumab como terapia de primera línea en los pacientes confirmados con SHUa o recurrencia de SHUa postrasplante.

2. Se debe considerar al eculizumab como estrategia terapéutica en los pacientes con MAT, en quienes no se observe respuesta terapéutica al intercambio plasmático o exista dependencia de esta terapia.

3. En nuestra opinión, dado que existe falta de estudios orientados a la duración ideal de la terapia, debe individualizarse cada caso y evitar suspender tratamientos por el riesgo de recaída.

\section{Conclusiones}

El SHUa es una enfermedad ultra-huérfana; más del $50 \%$ de los pacientes muere, necesita terapia de remplazo renal o sufre insuficiencia renal terminal dentro del primer año de diagnóstico. Es una enfermedad crónica por alteración en la regulación delsistema del complemento. La vía alterna siempre está "encendida" y puede auto amplificar su actividad bajo diferentes condiciones conocidas como amplificadoras del complemento (trauma, infecciones, entre otras). Lo anterior genera una respuesta inmune y hematológica inmediata, que lleva a lesión endotelial y estenosis vascular microangiopática, consolidando el diagnóstico de MAT que lleva a isquemia de múltiples órganos, incluyendo el riñón. El diagnóstico de SHUa es clínico y se sustentapor la exclusión de otras MAT primarias y en el análisis de las condicio- nes amplificadoras o enfermedades coexistentes, las cuales están presentes hasta en un 70\% de los casos.

Con el tratamiento de soporte actual (plasmaféresis o infusión de plasma) 9-15\% de los pacientes de SHUa mueren dentro del lapso de 1 año después de una manifestación clínica de hemólisis.Desde el 2011, se encuentra disponible eleculizumab, un anticuerpo monoclonal recombinante híbrido Ig2/ Ig4, totalmente humanizado dirigido contra el componente C5 del complemento humano. Múltiples estudios han demostrado su eficacia para controlar, de manera efectiva, la actividad aumentada del complemento, con mejoría clínica, hematológica, renal y sistémica, reflejada en la calidad de vida y pronóstico a largo plazo. Las consecuencias severas de esta enfermedad refuerzan la importancia del diagnóstico certero y adecuado de las diferentes MAT, pues 
su tratamiento difiere hoy en día, siendo el bloqueo de C5 un componente fundamental dentro del tratamiento temprano para el SHUa.

Agradecimientos

Los autores desean agradecer a Alexion Colombia por su apoyo al permitir las reuniones del Grupo Colombiano de Interés en SHUa y enfermedades del complemento. Su apoyo no influyó en lo consignado en este documento, el cual se deriva de la revisión de la literatura de manera objetiva por parte de los autores. Agradece también a la Asociación Colombiana de Nefrología e Hipertensión Arterial y a su Comité de Enfermedades Huérfanas, así como a la Asociación Colombiana de Nefrología Pediátrica por su reconocimiento y aval a este documento.

\section{Conflicto de intereses}

Los doctores Zilac Espitaleta, Luz Estela González, Milton Ibarra, Luis Alfonso Valderrama y Juan Pablo Córdoba, han recibido honorarios por charlas académicas en Síndrome Hemolítico Urémico atípico (SHUa) por parte de Alexion farmacéutica. El doctor Juan Pablo Córdoba ha servido como consultor externo para Alexion farmacéutica.

Este documento se encuentra avalado por la Asociación Colombiana de Nefrología Pediátrica (ACONEPE). Fue revisado por el Comité de Enfermedades Huérfanas de la Asociación Colombiana de Nefrología e Hipertensión (ASOCOLNEF).

No hay fuentes de financiamiento.

\section{Bibliografía}

1. Josep M. Campistol et al.: Actualización en síndrome hemolítico urémico atípico: diagnóstico y tratamiento. Documento de consenso; Nefrología 2013;33(1):27-45.

2. Noris, M., Caprioli, J., Bresina, E., Mossali, C., Pianetti, G., et al. Relative Role of genetic Complement abnormalities in Sporadic and Familial aHUS and Their Impact on Clinical Phenotype. Clin J Am Soc Nephrol 5(10):1844 -1859, 2010.

3. Noris, M., Remuzzi G. Atypical hemolytic-uremic syndrome. N Engl J Med, 2009;361(17):1676-1687.

4. Noris M,. Bucchioni S,. Galbusera $\mathrm{M}$ et al. Complement factor $\mathrm{H}$ mutation in familial thrombotic thrombocytopenic purpuraeith ADAMTS13 deficiency and renal involvement. J Am Soc Nephrol, 2005;16(5):1177-1183.

5. Taylor CM, Machin S, Wigmore SJ, Goodship TH. Clinical practice guidelines for the management of atypical haemolytic uraemic syndrome in the United Kingdom. Br J Haematol, 2010;148(1):37-47.

6. Keating G. Eculizumab: A Riview of its use in atypical haemolytic uremic syndrome. Drugs, 2013;73(18):2053-2066.

7. Caprioli, J., Noris, M., Brioschi, S., Pianetti, G., Castelletti, F., et al. Genetics of HUS: the impact of MCP, CFH, and IF mutations on clinical presentation, response to treatment and outcome. Blood 2006;108:1267-1279.

8. Constantinescu AR, Bitzan M, Weiss LS, et al. Non-enteropathic hemolytic uremic syndrome: causes and short-term course. Am J Kidney Dis, 2004;43(6):976-982.

9. Vesely SK, George JN, Lammle B, et al. ADAMTS13 activity in thrombotic thrombocytopenic purpura-hemolytic uremic syndrome: relation to presenting features and clinical outcomes in a prospective cohort of 142 patients. Blod, 2003;102(1):60-68.

10. Neuhaus TJ, Calonder S, Leumann EP. Heterogeneity of atypical haemolytic uraemic syndromes. Arch Dis Child, 1997;76(6):518-521.

11. George JN, Kremer Hovinga JA, Terrell DR, Vesely SK, Lammle B. The Oklahoma Thrombotic Thrombocytopenic Purpura-Hemolytic Uremic Syndrome Registry: The Swiss connection. Eur J Haematol, 2008;80(4):277-286.

12. Langman C. Systemic multi-organ complications in atypical haemolytic uremic syndrome (aHUS): Retrospective 
study in a medical practice setting. European Hematology Association, Abstract 409, 2012;June 14-17.

13. Sellier-Leclerc AL, Fremeaux-Bacchi V, Dragon-Durey MA, et al. Differential impact of complement mutations on clinical characteristics in atypical hemolytic uremic syndrome. J Am Soc Nephrol, 2007;18(8):2392-2400.

14. Bu F, Borsa N, Gianluigi A, et al. Familial atypical Hemolytic Uremic Syndrome: a Review of its genetic and clinical aspects. Clinical and Developmental Immunology, 2012; Pag 1-9.

15. Schmidtko J, Peine S, El-Housseini Y, Pascual M, and Meier P, et al. Treatment of Atypical Hemolytic Uremic Syndrome and Thrombotic Microangiopathies: A focus on Eculizumab. Am J Kidney Dis, 2013;61(2):289-299.

16. Meri S. Complement activation in diseases presenting with thrombotic microangiopathy.Eur J Intern Med, 2013;24 (6):496-502.

17. Heinen S, Pluthero FG, van Eimeren VF, Quaggin SE, Licht C. Monitoring and modeling treatment of atypical hemolytic uremic syndrome. Molecular Immunology, 2013;54(1):84-88.

18. Cofiell R, Kukreja A, Bedard K, et al. Biomarkers of complement activation, inflammation, endothelial activation and damage, thrombosis and renal injury in patients with atypical hemolytic uremic syndrome (aHUS) prior to and during treatment with eculizumab. American society of Hematology, Abstract/poster Presentation Number 2184, 2013.

19. Loriat C, Fremeaux-Bacchi V. Atypical hemolytic uremic syndrome. Orphanet Journal of rare Diseases, 2011;6(1):60.

20. Ve'ronique Fremeaux-Bacchi et al.: Genetics and Outcome of Atypical Hemolytic Uremic Syndrome: A Nationwide French Series Comparing Children and Adults; Clin J Am Soc Nephrol, Vol 8 April, 2013.

21. Guo X, Nzerue C. How to prevent, recognize, and treat drug/induced nephrotoxicity. Cleve Clin J Med, 2002;69(4):289-4, 296.

22. Blake-Haskins JA, Lechleider RJ, Kreitman RJ. Thrombotic microangiopathy with targeted cancer agents. Clin Cancer Res, 2011;17(18):5858-5866.

23. Marik PE, Rivera R. Hypertensive emergencies: an update. Curr Opin Crit Care, 2011;17(6):569-580.

24. Van den born BJ, Honnebier UP, koopmans RP, van Montfrans GA. Microangiopathic hemolysis and renal failure in malignant hypertension. Hypertension, 2005;45(2):246-251.

25. Devinsky O, Petito CK, Alonso DR. Clinical and neuropathological findings in systemic lupus erythematosus: the role of vasculitis, herat emboli, and thrombotic thrombocytopenic purpura. Ann Neurol, 1998;23(4):380-384.

26. Mok C, Raymond C, Kwok L, et al. Effect of renal disease on the standardized mortality ratio and life expectancy of patients with systemic lupus erythematousus. Arthritis and Rheumatism, 2013;65 (8):2154-2160.

27. Richani K, soto E, Romero R, et al. Normal pregnancy is characterized by systemic activation of complement system. J Matern Fetal Neonatal Med, 2005;17(4):239-245.

28. Goodship THJ, Kavanagh D. Pulling the trigger in atypical hemolytic uremic syndrome: the role of pregnancy. Journal of the American Society of nephrology, 2010;21(5):731-732.

29. Kakhouri F, Roumenina L, Provot F, et al. Pregnancy-associated hemolytic uremic syndrome revisited in the era of complement gene mutations. J Am soc Nephrol, 2010;21(5):859-867.

30. Salmon JE, Heuser C, Triebwasser M, et al. Mutations in complement regulatory proteins predispose to preeclampsia: a genetic analysis of the PROMISSE cohort. PLoS Med, 2011;8(3):e1001013.

31. Coppo P, Schwarzinger M, Buffet M, et al. Predictive features of severe acquired ADAMTS13 deficiency in idiopathic thrombotic microangiopathies: the French TMA Reference Center Experience. PLoS ONE, 2010;5(4): e10208.

32. Ferrari S, Scheiflinger F, Rieger M, et al. Prognostic value of anti-ADAMTS 13 antibody features (Ig isotype, titer, and inhibitory effect) in a cohort of 35 adult French patients undergoing a first episode of thrombotic microangiopathy with undetectable ADAMTS 13 activity. Blood, 2007;109(7):2815-2822.

33. Cataland SR, Yang S, Wu HM. The use of ADAMTS13 activity, platelet count, and serum creatinine to differentiate acquired thrombotic thrombocytopenic purpura from other thrombotic microangiopathies. British Journal of Haematology, 2012;157(4):501-503. 
34. Bentley MJ, Lehman CM, Blaylock RC, Wilson AR, Rodgers GM. The utility of patient characteristics in predicting severe ADAMTS13 deficiency and response to plasma exchange. Transfusion, 2010;50(8):1654-1664.

35. Rodríguez de Córdoba, S., Montes, T. Síndrome hemolítico urémico atípico. Nefrologia Sup Ext 2011;2(81):58-65.

36. Westra, D., Wetzwlwa, JFM., Volokhina, EB., van den Heuvel, LP., van de Kar., NCAJ. A new era in the diagnosis and treatment of atypical haemolytic uraemic syndrome. Netherlands The Journal of Medicine 3: Vol 70, pag 121-129, 2012.

37. Richards A, Kemp EJ, Liszewski MK, Goodship JA, Lampe AK, Decorte R, Müslümanoğlu MH, Kavukcu S, Filler G, Pirson Y, Wen LS, Atkinson JP, Goodship TH. Mutations in human complement regulator, membrane cofactor protein (CD46), predispose to development of familial hemolytic uremic syndrome.Proc Natl Acad Sci U S A. 2003 Oct 28;100(22):12966-71. Epub 2003 Oct 17.

38. Bu, F., Borsa, N., Gianluigi, A., Smith, RJH. Familial Atypical Hemolytic Uremic Syndrome: A review of Its Genetic and Clinical Aspects. Clinical and developmental Immunology. Vol 2012, Article ID 370426, 9 pages.

39. Caprioli J, Bettinaglio P, Zipfel PF, Amadei B, Daina E, Gamba S, et al. The molecular basis of familial hemolytic uremic syndrome: mutation analysis of factor $\mathrm{H}$ gene reveals a hot spot in short consensus repeat 20. J Am Soc Nephrol 2001;12(2):297-307.

40. Fremeaux-Bacchi, V., Fakhouri, F., Garnier, A., Bienaimé, F., Dragón-Durey, M., Ngo, S., et al. Genetics and Outcome of Atypical Hemolytic Uremic Syndrome: A Nationwide French Series Comparing Children and Adults. Clin J Am Soc Nephrol 8: xxx-xxx(Falta información?), 2013. Doi: 10.2215/CJN.04760512.

41. Delvaeye, M., Noris, M., De Vriese, A., Esmon, CT., Esmon, NL. Thrombomodulin mutations in Atypical Hemolytic-Uremic Syndrome. N Engl J Med 2009;361:345-357.

42. De Jorge, E. G. et al. The development of atypical hemolytic uremic syndrome depends on complement C5. J. Am. Soc. Nephrol 2011;22:137-145.

43. Pickering, M. C. et al. Spontaneous hemolytic uremic syndrome triggered by complement factor $\mathrm{H}$ lacking surface recognition domains.J. Exp. Med. 2007;204:1249-1256.

44. Clark WF. Thrombotic microangiopathy: Current knowledge and outcomes with plasma exchange. Seminars in dialysis, 2012;25(2):214-219.

45. Heinen S, Pluthero FG, van Eimeren VF, Quaggin SE, Licht C. Monitoring and modeling treatment of atypical hemolytic uremic syndrome. Molecular Immunology, 2013;54(1):84-88.

46. Riedl M, Hofe J, rosales A, Wurzner R, and Jungraithmayr T. Acute manifestation and 1 year follow up of a big cohort of patients with atypical hemolytic uremic syndrome (aHUS). J am Soc Nephrol, 2011; 22.(faltan las páginas)

47. Taylor CM, Chua C, Howie AJ, Risdon RA.Clinico-pathological findings in diarrhea-negative haemolytic uraemic syndrome. Pediatric Nephrology, 2004;19(4):419-425.

48. Delmas Y, Loirat C, Muus P, et al. Eculizumab (ECU) in atypical hemolytic uremic syndrome (aHUS) patients with long disease duration and chronic kidney disease (CKD): sustained efficacy at 3 years. American Society of Nephrology, Kidney week, 2013.

49. Greenbaum L, Babu S, Furman R, et al. Continued improvements in renal function with sustained Eculizumab (ECU) in patients with atypical hemolytic uremic syndrome (aHUS) resistant to plasma exchange/infusion (PE/PI). J Am Soc Nephrol, 2011a; 22. (faltan las páginas)

50. Licht $\mathrm{C}$, Muus $\mathrm{P}$, Legendre $\mathrm{C}$, et al. Ph II study of Eculizumab in patients with atypical hemolytic uremic syndrome (aHUS) receiving chronic plasma exchange/infusion (PE/PI). American Society of Nephrology, Abstract TH-PO366, 2011a.

51. Muus P, Legendre C, Douglas K, et al. Safety and efficacy of Eculizumab in aHUS patients on chronic plasma therapy: Interim analysis from a phase II trial. American Society of Nephrology meeting, Renal Week 2010, Denver, CO. J Am Soc Nephrol, 2010.

52. Gaber O, Loirat C, Greenbaum L, et al. Eculizumab maintains efficacy in atypical hemolytic uremic syndrome (aHUS) patients with progressing thrombotic microangiopathy (TAM): 3 year update. American Society of Nephrolo- 
gy Kidney Week, 2013.

53. Vilalta R, Al-Akash S, Davin JC, et al. Eculizumab therapy for pediatric patients with atypical haemolytic uremic syndrome: Efficacy and safety outcomes of a retrospective study. European Hematology Association, Abstract 115, 2012.

54. Legendre C, Licht C, Muus P, et al. Terminal Complement inhibitor Eculizumab in atypical Hemolytic Uremic syndrome. N Engl J Med, 2013;368:2169-81.

55. Fakhouri F, Hourmant M, Campistol J, et al. Eculizumab inhibits thrombotic microangiopathy and improves renal function in adult atypical hemolytic uremic syndrome patients. American Society of Nephrology, Kidney Week, 2013.

56. Electronic Medicines Compendium.Soliris-Summary of Product Characteristics [online], http://www.medicines.org. uk/emc/medicine/19966/SPC/soliris/ (2012).

57. U. S. Food and Drug Administration. Highlights of Prescribing Information: Soliris [online], http://www.accessdata. fda.gov/drugsatfda_docs/label/2011/125166s172lbl.pdf (2011). 